\title{
Near wake Reynolds-averaged Navier-Stokes predictions of the wake behind the MEXICO rotor in axial and yawed flow conditions
}

\author{
Sørensen, Niels N.; Bechmann, Andreas; Réthoré, Pierre-Elouan; Zahle, Frederik
}

Published in:

Wind Energy

Link to article, DOI:

10.1002/we.1559

Publication date:

2014

Link back to DTU Orbit

Citation (APA):

Sørensen, N. N., Bechmann, A., Réthoré, P-E., \& Zahle, F. (2014). Near wake Reynolds-averaged

Navier-Stokes predictions of the wake behind the MEXICO rotor in axial and yawed flow conditions. Wind Energy, 17(1), 75-86. https://doi.org/10.1002/we.1559

\section{General rights}

Copyright and moral rights for the publications made accessible in the public portal are retained by the authors and/or other copyright owners and it is a condition of accessing publications that users recognise and abide by the legal requirements associated with these rights.

- Users may download and print one copy of any publication from the public portal for the purpose of private study or research.

- You may not further distribute the material or use it for any profit-making activity or commercial gain

- You may freely distribute the URL identifying the publication in the public portal 


\title{
Near Wake RANS Predictions of the wake Behind the MEXICO Rotor in Axial and Yawed Flow Conditions
}

\author{
Niels N. Sørensen, A. Bechmann, P-E. Réthoré, F. Zahle \\ DTU Wind Energy, Technical Uni. Denmark \\ DK-4000 Roskilde, Denmark
}

September 28, 2012

\begin{abstract}
In the present paper Reynolds-Averaged Navier-Stokes (RANS) predictions of the flow field around the MEXICO rotor in yawed conditions are compared with measurements. The paper illustrates the high degree of qualitative and quantitative agreement that can be obtained for this highly unsteady flow situation, by comparing measured and computed velocity profiles for all three Cartesian velocity components along four axial transects and several radial transects.
\end{abstract}

\section{Introduction}

During the last 10 years there has been an increasing focus on the capability to predict the wake behavior in large-scale wind turbine parks. An essential component to wake predictions within wind turbine parks is the ability to correctly predict the near wake development as a function of the rotor loads. A review addressing wind turbine wake aerodynamics can be found in the review paper of Vermeer et al. [1], where both the experimental and general computational approaches are being discussed, while the more recent review of Sanderse et al. [2] addresses typical CFD approaches to wake prediction. For more details on the early work on Navier-Stokes based rotor aerodynamics, see the chapter on Rotor Aerodynamics by Sørensen [3]. In contrast to the widespread axial flow predictions of wind turbine rotors that can be predicted using a steady-state technique and cyclic conditions limiting the computational domain to one third for a three-bladed rotor, yawed flow computations requires transient computations and a domain resolving the full rotor geometry. Yawed flow computations have been performed, for e.g. the NREL Phase-VI rotor see the works of Xu and Sankar [4], Sørensen [5], Madsen et al. [6], Tongchitpakdee et al. [7] and for the Nordtank NTK 500/41 turbine the work of Zahle and Sørensen [8]. As a CFD simulation only requires information about the rotor geometry and the operational conditions, it has the potential to provide valuable information for engineering wake models and for the simplified rotor descriptions as used in the actuator line (AL) models by Sørensen and Shen [9] and in actuator disc (AD) models as described in Sørensen and Myken [10]. The engineering models and the AL/AD models can then be used for full scale park computations, where the geometry resolving CFD method is not practical. The present paper aims at establishing the quality of geometry resolving CFD simulation, based on comparison with actual measurements, and is connected to the work from 2009 reported in Bechmann et. al [11] and Réthoré et al. [12]. Related studies for the axial flow situation is reported in the work of Lutz et al. [13] using a compressible flow solver, 
and for the axial and yawed conditions using a free wake lifting line code in the work of Grasso and van Garrel [14].

\section{Code description}

The in-house flow solver EllipSys3D is used for both axial and yaw computations. The code is developed in co-operation between the Department of Mechanical Engineering at the Technical University of Denmark and The Department of Wind Energy at Risø National Laboratory. See the work of Michelsen [15, 16] and Sørensen [17]. The EllipSys3D code is a multi-block finite volume discretization of the incompressible Reynolds-Averaged Navier-Stokes (RANS) equations in general curvilinear coordinates.

For the yaw computations the unsteady solution is advanced in time using a 2nd-order iterative time-stepping (or dual time-stepping) method, while the axial flow cases are computed using a steady-state approach. The transient yaw computations are performed with a time step of $1 \times$ $10^{-4} \mathrm{~s}$ or approximately 1400 time steps per revolution, using 6 sub-iterations in each time step. The convective terms are discretized using a third-order Quadratic Upstream Interpolation for Convective Kinematics (QUICK) scheme by Leonard [18], while central differences are used for the viscous terms.

All solutions in the present work are obtained using a moving mesh methodology. The moving mesh option is used even for the steady-state case were a 'Steady state moving mesh algorithm' is used, see Sørensen [19]. In the present work the turbulence in the boundary layer is modeled by the k- $\omega$ Shear Stress Transport (SST) eddy viscosity model by Menter [20]. Even though both fully turbulent and transitional computations were performed during the study, only the fully turbulent conditions are shown, as the experimental conditions were tripped to enforce transition to turbulent flow.The equations for the turbulence model are solved after the momentum and pressure correction equations in every sub-iteration/pseudo time step.

\section{Computational grid}

The full three-bladed rotor is modeled in order to use the same mesh for both axial and yawed inflow conditions, but the tower and nacelle geometry have been neglected. The mesh is an O-Otopology where the individual blades are meshed with 256 cells around the blade chord, 128 cells in the spanwise direction and a $64 \times 64$ cells block at the blade tip. In the normal direction, 256 cells are used with high concentration of cells within the first 1-2 diameters away from the rotor, see Figure 1. The height of the cells at the wall is $\sim 5 \times 10^{-6} \mathrm{~m}$ in order to resolve the boundary layers and ensure $y^{+}$values around 1 . The outer boundary of the domain is located $\sim 40 \mathrm{~m}$ from the rotor center or approximately 10 rotor diameters away. The grid generation is performed with the 3D enhanced hyperbolic grid generation program HypGrid3D which is a $3 \mathrm{D}$ version of the 2D hyperbolic grid generator described in the report of Sørensen [21].The total number of cells used is 28.3 million cells, see Figure 1. The mesh used consists of 864 blocks.

Inlet conditions corresponding to the described cases are specified at the upstream part of the outer boundary, see Figure 1, while outlet conditions corresponding to a fully developed flow assumption are used at the downstream part of the outer domain boundary. No-slip conditions are applied at the rotor surface. 


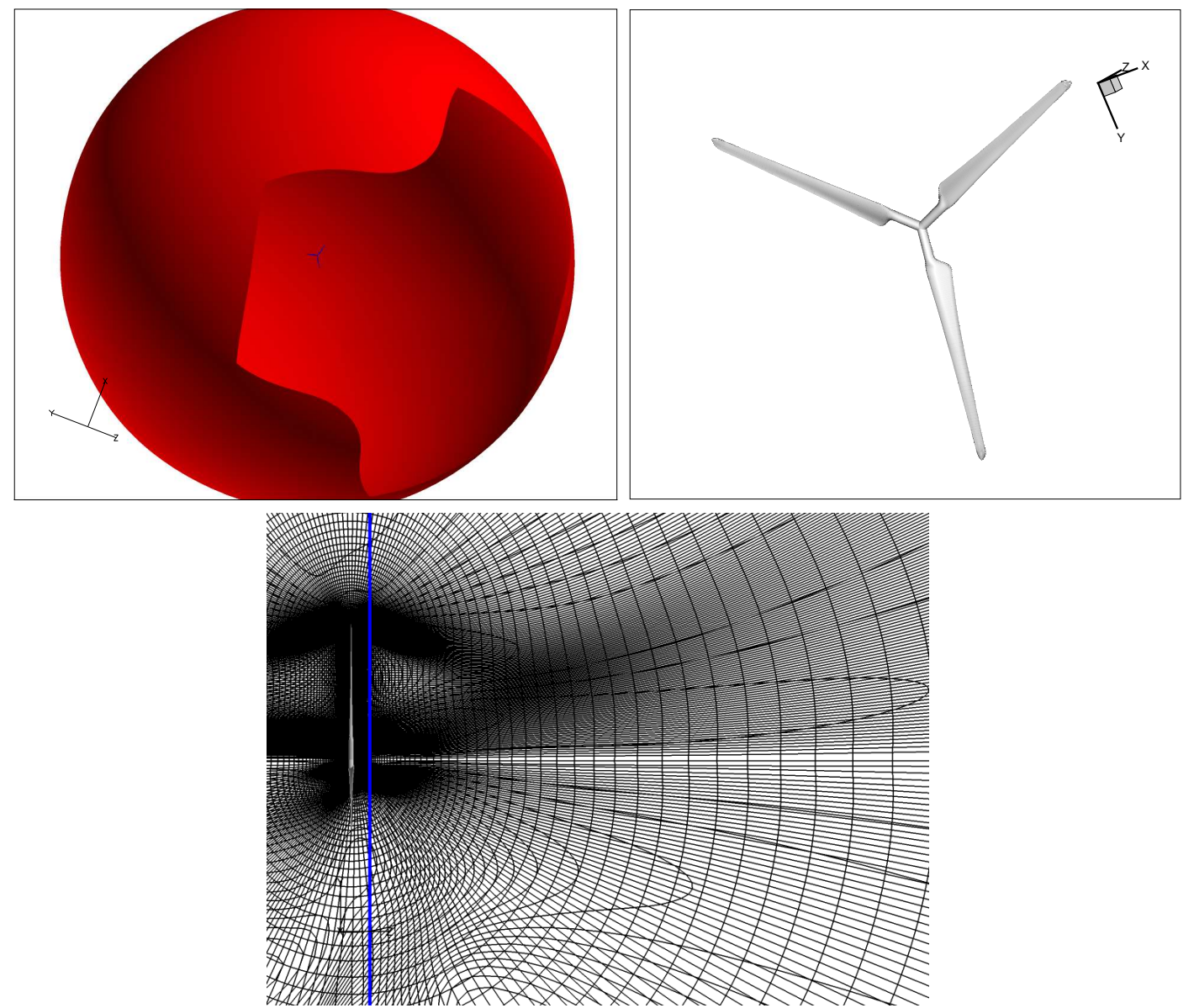

Figure 1: Top left figure shows the computational domain with the inflow part of the boundary in red, the rotor at the center of the domain in grey looking through the outlet part of the outer boundary. The top right figure shows a close-up of the rotor-only geometry used in the computations. Finally, the bottom figure shows the wake resolution and the axial location of the plane where the radial profiles are extracted.

\section{Present Study}

In the present study the focus is on a series of cases from the MEXICO experiment described in the articles by Snel et al. [22] and the report by Schepers and Snell [23], that were selected within the IEA Task 29. As stated in connection with the description of the computational grid the present study is based on rotor-only computations, neglecting the influence of tower, nacelle and possible wind tunnel interference. The rotor blade geometry is based on the original theoretical rotor design, as the measured geometry of the manufactured blade was not available at the time of this study. The three-bladed rotor has a diameter of $4.5 \mathrm{~m}$, with a blade geometry constructed from a combination of DU-91-W2-250 airfoils at the inner part, Ris $\varnothing$-A21 at the central part and NACA 64-418 airfoils on the outer part. In the MexNext Annex under IEA, three axial cases at $10,15,24 \mathrm{~m} / \mathrm{s}$ were computed, along with a yaw case at $15 \mathrm{~m} / \mathrm{s}$ wind speed with a yaw angle of 30 degrees. For all cases, the rotor pitch was set at -2.3 degrees turning the leading edge away from the incoming wind. The rotational speed was fixed at $424.5 \mathrm{rpm}$. In the present work, the focus is on the development of the wake flow for the $15 \mathrm{~m} / \mathrm{s}$ case in axial and yawed conditions. The measured loads shown below are based on the the five radial pressure sections measured 

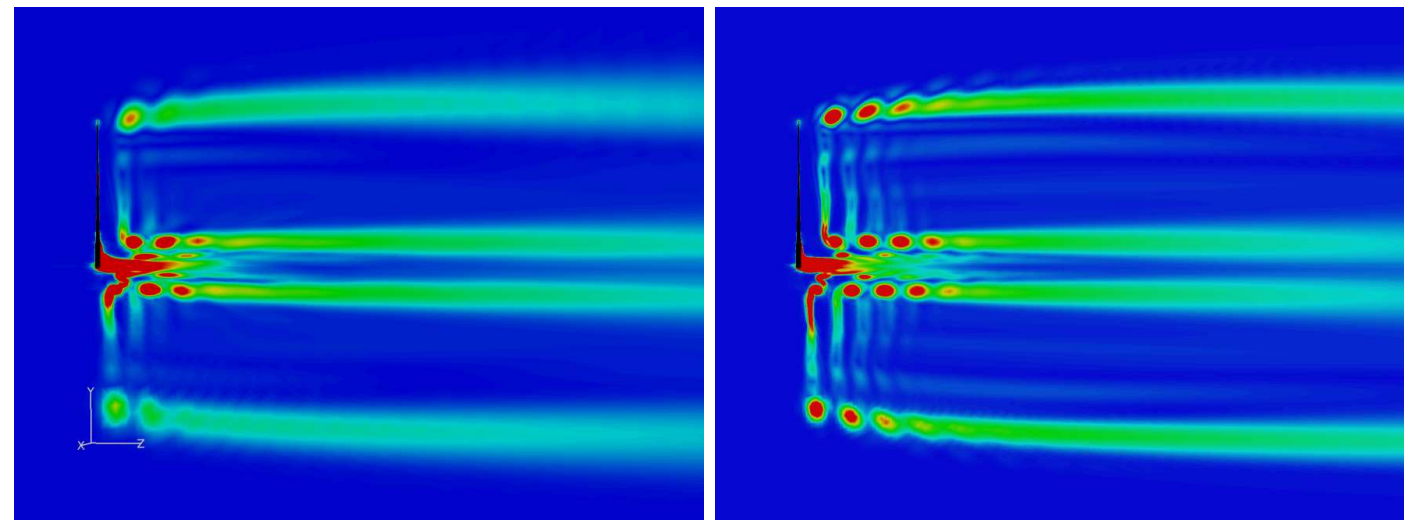

Figure 2: Absolut value of the vorticity in the wake of the rotor, left figure shows the present computation, while the right figure shows the computation on a grid of nearly doubled resolution.

during the experiment. The load measurements from the MEXICO experiment have been subject to a substantial discussion. As can be seen in Table 1, there is a relatively large discrepancy between measurements and computations even at the design point of $15 \mathrm{~m} / \mathrm{s}$. This was not only observed in the present study, but similar studies by other groups using Blade Element Momentum codes, Lifting Line codes, and other Navier-Stokes based CFD solvers indicat similar degree of agreement. As a large deviation in the load may result in large deviations in the wake patterns, the high load deviation may raise concern about the possibility of accurately capturing the wake flow. During the MexNext project, investigations by the authors showed that the agreement between measured and predicted wake patterns using an $\mathrm{AD}$ method for the axial flow cases with the load given by a full CFD simulation, was clearly superior to results using loads based on measured values, see Figure 6 in the paper of Réthoré et al. [12]. Trying to match the measured load distributions additional CFD computations were performed, varying both the wind speed and the rotor tip pitch. These computations, were unable to match the measured loads. With respect to grid convergence of the present computation, a comparison for the $15 \mathrm{~m} / \mathrm{s}$ axial case was done with a solution on a mesh with nearly the double amount of point in all direction, resulting in a mesh of around 141 million cells. This comparison shows that the variation in the computed thrust and torque is less than $1 \%$, indicating that with respect to the integrated loads the results are fairly grid independent. Comparing the wake profiles, see Figure 3 and 2, a very good agreement is seen between the present grid and the refined grid (141 million points). The most pronounced deviation is the tip vortex strength, which seems to be slightly overpredicted on the fine mesh.

To give a qualitative indication of the yaw computations, the computed normal and tangential force at the 85 percent section is shown in Figure 4. Both measured and computed values are based on surface pressure measurements. It is evident from both the normal and tangential force that there is an offset in the level between the measurements and the computations, while the amplitude of the load variation is reasonabely well predicted. Besides the offset in level, the computed forces are phase shifted so the peaks in the computations appear slighty later than in the measurements.

\section{Results}

Before discussing the actual comparison of the measured and computed values, a few definitions will be given. The rotational direction is clock-wise, when looking along the rotor axis in the flow direction. The blade azimuth angle is defined as zero for blade one pointing straight up. 


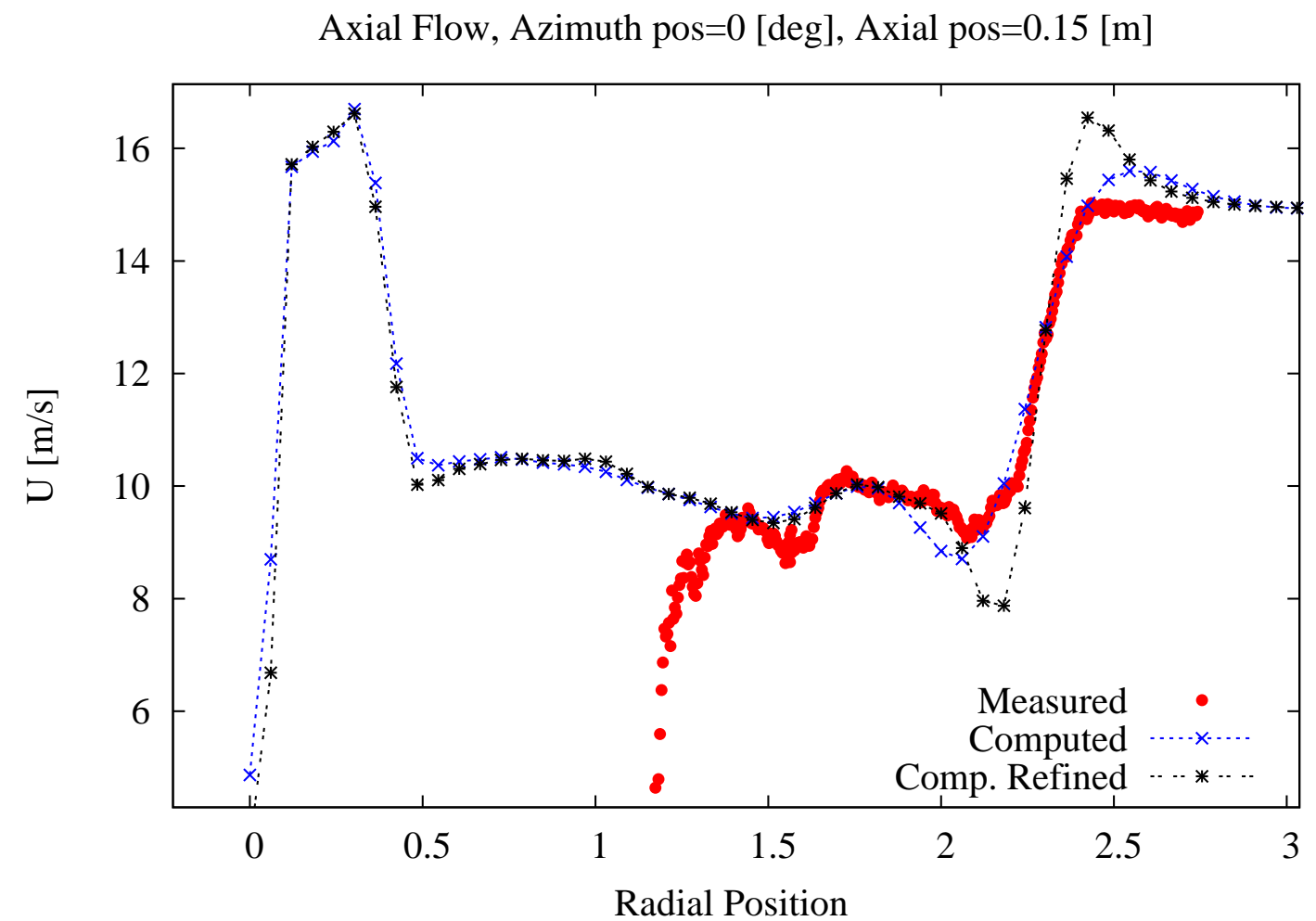

Figure 3: Axial velocity in the wake of the rotor, comparing the present solution with a solution on a nearly doubled grid resolution
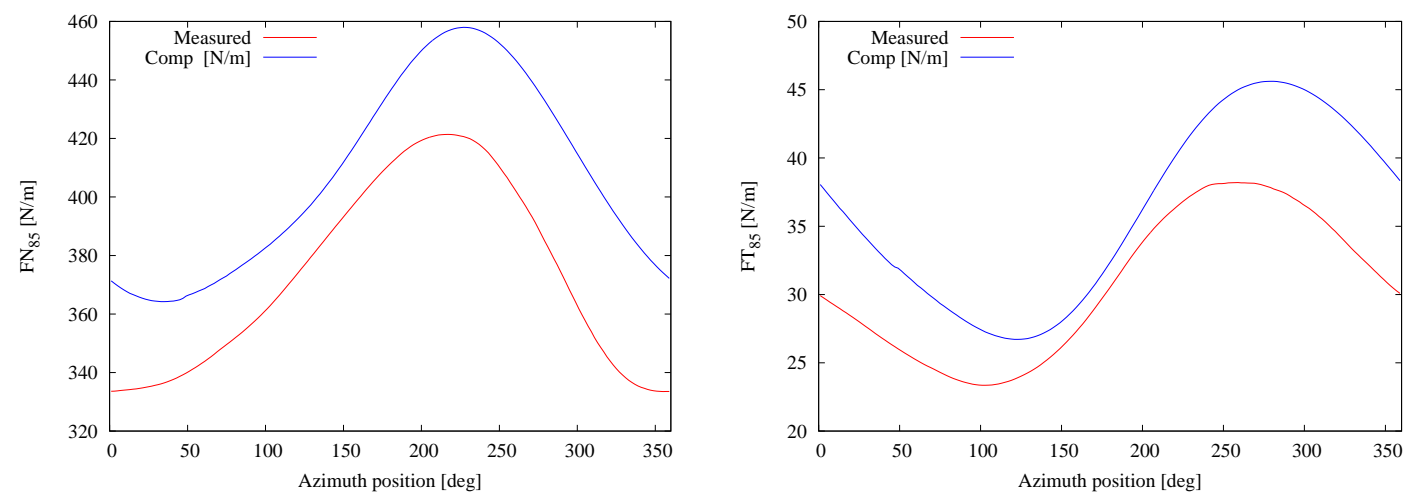

Figure 4: Comparison of the azimuth variation of the normal and tangential force at the $85 \%$ section between the present computations and the forces measured in the experiment. 
Table 1: Comparison of measured and integral rotor loads for the three axial flow cases.

\begin{tabular}{|c|c|c|c|c|}
\hline Velocity $[\mathrm{m} / \mathrm{s}]$ & $\begin{array}{l}\text { Meas. } \\
\text { Thrust [N] }\end{array}$ & $\begin{array}{l}\text { Comp. } \\
\text { Thrust [N] }\end{array}$ & $\begin{array}{c}\text { Meas. } \\
\text { Torque }[\mathrm{Nm}]\end{array}$ & $\begin{array}{c}\text { Comp. } \\
\text { Torque }[\mathrm{Nm}]\end{array}$ \\
\hline 10 & 854.0 & 1007 & 61.1 & 73 \\
\hline 15 & 1516.8 & 1742 & 284.6 & 327 \\
\hline 24 & 2173.2 & 2392 & 695.0 & 735 \\
\hline
\end{tabular}

The velocities reported in the present study are given with respect to the wind tunnel coordinate system, with the U-velocity along the $x_{\text {tunnel }}$-axis pointing in the flow direction, the V-velocity along the $y_{\text {tunnel }}$-axis perpendicular to the flow direction and the $\mathrm{W}$-component along the $\mathrm{z}$-axis pointing vertically up.

When comparing the axial and radial profiles of the velocity components, all profiles are extracted in the horizontal plane at the height of the rotor axis.In the experiment the velocity profiles were extracted using stereoscopic Particle Image Velocimetry (PIV), for more details see the report of Schepers, Pascal and Snel [24].

The axial profiles are extracted for rotor positions corresponding to situations where a blade has passed the extraction plane 90 degrees earlier. For the positive $y_{\text {tunnel }}$-positions this can be obtained with blade one at zero azimuth position. For the negative $y_{\text {tunnel }}$-values, a similar situation is observed when blade one is at 60 degrees azimuth position. For the radial profiles, comparisons are shown for several azimuth positions $[40,80,120]$ degrees for illustration purpose, and neglecting some of the intermediate azimuth positions for brevity.

For the yaw case, one can observe that the profiles extracted along the lines at positive $y_{\text {tunne }}$ values will intersect the rotor plane upstream of $x_{\text {tunnel }}=0$, while the intersection happens downstream of $x_{\text {tunnel }}=0$ for the negative $y_{\text {tunne }}$-values.
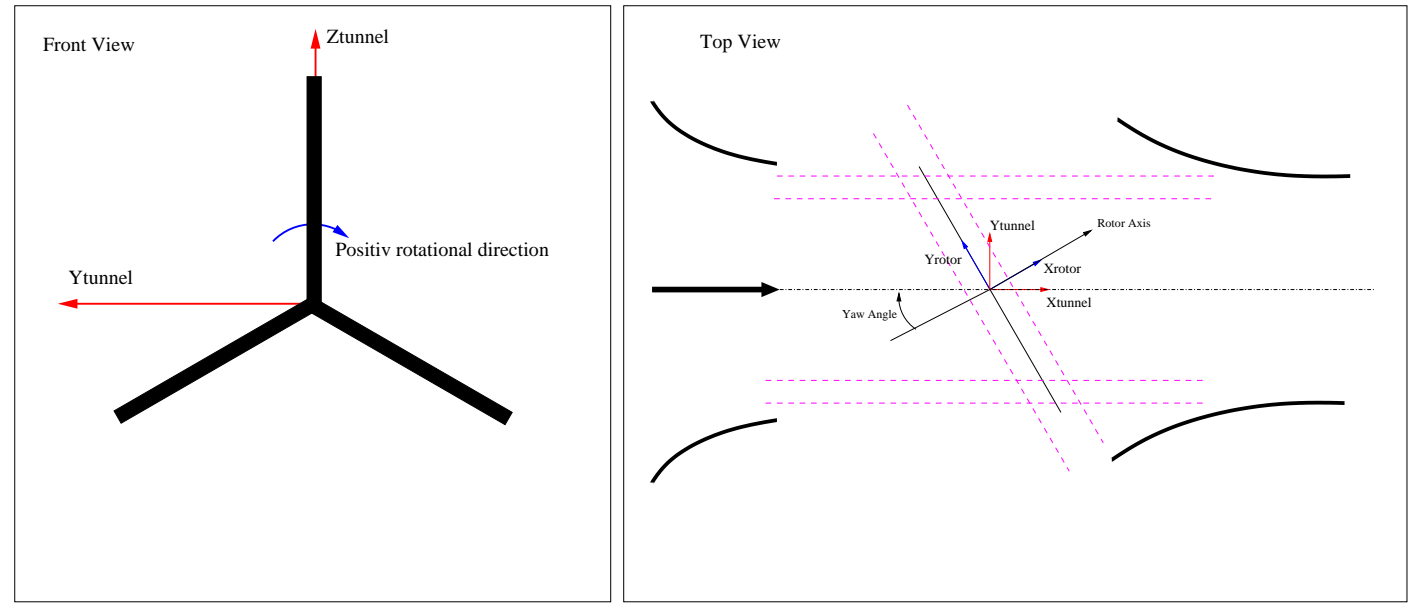

Figure 5: A schematic of the tunnel setup for the yaw computations, indicating both the tunnel and rotor coordinate system. Zero azimuth is when blade one is pointing vertically up, with the rotational direction clockwise looking along the rotor axis. 


\section{Axial velocity profiles}

Looking firstly at the axial profiles extracted in situations where the blade has passed the horizontal extraction plane 90 degrees earlier, the axial flow case at $15 \mathrm{~m} / \mathrm{s}$ is seen in the two top frames of Figure 6. Here the overall shape is predicted quite well. Similarly good agreement with measured values is observed for the two yawed cases with respect to the axial transects at negative $y$-values, center frames of Figure 6 . For the positive $y$-values the agreement is not very good, especially for the transect at $\mathrm{y}=1.37 \mathrm{~m}$. The error for the axial flow case and for the negative $y$-values of the yawed case is at maximum $20 \%$ and for most cases much less than $10 \%$. In the yawed case, at positive $y$-values, high errors are observed for $y=1.37 \mathrm{~m}$ in the region between 1.5 and $4 \mathrm{~m}$ downstream of the rotor plane, bottom left frame of Figure 6. The explanation of this is that the relatively large nacelle of the MEXICO rotor disturbes the wake flow in this region. This is strongly supported by Figure 15 in the report of Schepers, Pascal and Snel, where the obstruction of the modeled nacelle is clearly visible. At the more outboard station $(y=1.85 \mathrm{~m})$, where the nacelle has less influence the error is again decreased considerably, see Figure 6 bottom right frame. This indicates that in future studies of the MEXICO rotor in yaw, the nacelle geometry needs to be included. For the radial flow component for the axial and 30 degrees yaw case, shown in Figure 7, the agreement is again very good. Also here, the effect of the nacelle of the MEXICO rotor can be observed in the measured values at positive $y$-values. Similar conclusions can be drawn with respect to the agreement of the tangential flow component shown in Figure 8. The high frequency oscillation in the axial direction present in all three velocity components are related to the intersection of the transect with the discrete wake sheets behind the three rotor blades. The wake sheets can clearly be seen in the snap shots of the wake in Figure 2. Due to the limited grid resolution the oscillations in the computations are disapering faster than in the measurements. Additionally an interesting phenomenon to observe is the high rotation present in the wake as far downstream as measurements are available. This may have great implications for measurements of yaw alignment using nacelle based anemometers, which will be influenced by this wake rotation, see the article by Zahle and Sørensen [8].

\section{Radial velocity profiles}

Having looked at the axial development of the flow, next the focus is shifted to the radial profiles right upstream and downstream of the rotor for the yaw case. As seen from Figure 5, the radial profiles are extracted parallel to the rotor disc, and the distance is $0.15 \mathrm{~m}$, corresponding to only 7 percent of the rotor radius. The figures of radial profiles to be discussed show the profile just upstream in the left column, and the profile just downstream in the right column. In the measurements, data were available for each 10 degree of azimuth position of the rotor, for brevity only a few of these stations are shown in the present study, namely the 40, 80 and 120 degree positions.

Starting by the axial flow component (U-velocity), generally good agreement can be observed both upstream and downstream of the rotor, see Figure 9. Comparing the upstream profiles and the downstream profiles, it is obvious that the upstream profiles only are influenced by the induction of the rotor. This is in good agreement with the physics, and give profiles that are smooth in the radial direction. In contrast, the downstream profiles clearly show signs of the discrete structures such as tip vortices. Looking at the downstream profiles, the tip vortex after blade two is clearly seen around $y=2.25 \mathrm{~m}$ in the top right frame, where the blade has just passed the extraction position 10 degrees before the snapshot was taken. Similar for the bottom right frame around $y=-2.3 \mathrm{~m}$, where again a strong signal is visible from the blade passage around 30 degrees before taking the snapshot. Unfortunately, the measurements do not allow comparison of data closer to the center of the rotor, as the PIV equipment used for the MEXICO measurements were not 

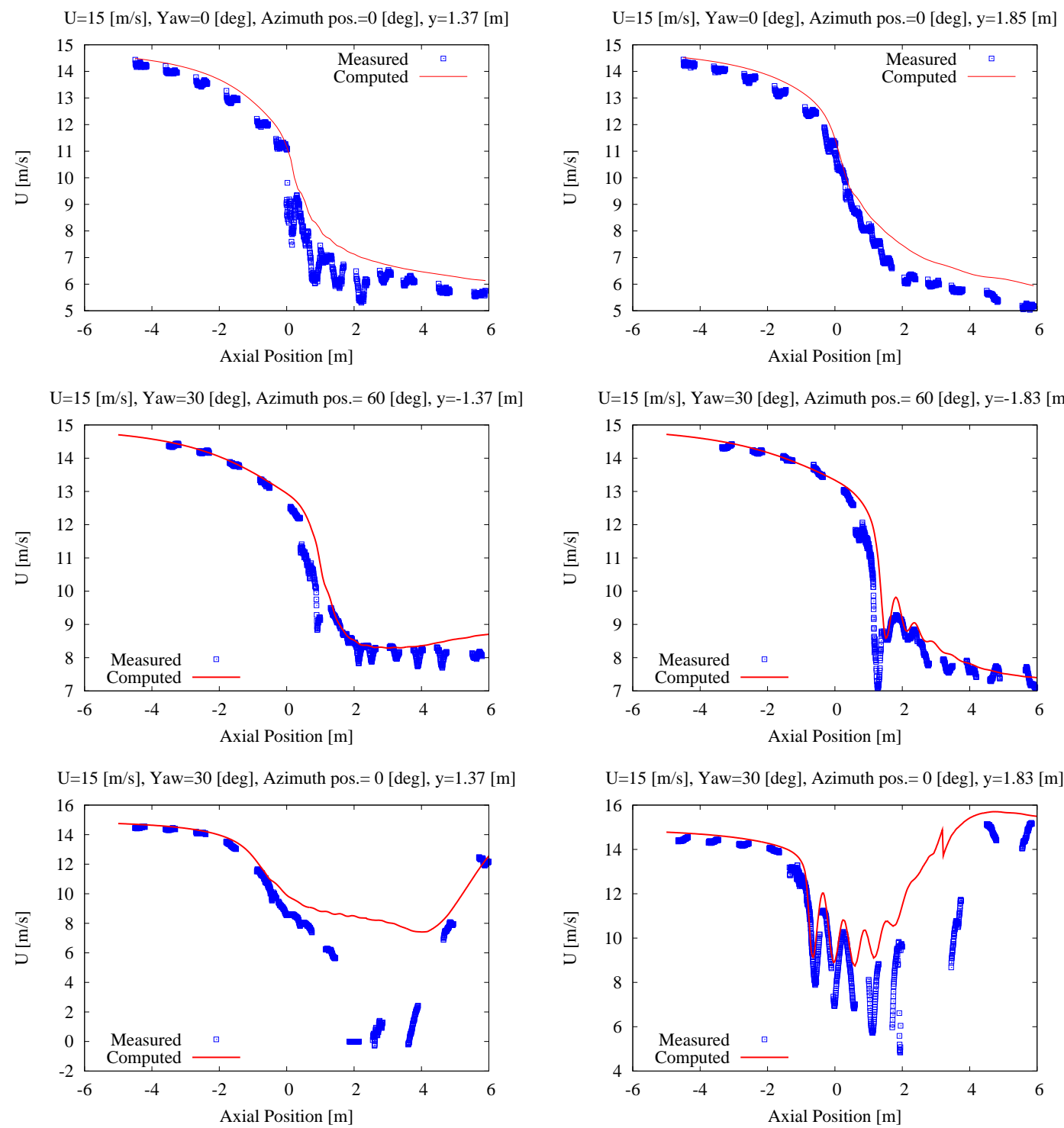

Figure 6: Comparison of axial transects of measured and computed U-velocity in the horizontal plane for the $15 \mathrm{~m} / \mathrm{s}$ axial flow case, top row. The center and bottom row show the $15 \mathrm{~m} / \mathrm{s}$ 30 degrees yaw case for negative and positive $y$-values respectively. The left column shows the inner most line $\mathrm{y}=+/-1.37 \mathrm{~m}$ while the right column shows the outermost line $\mathrm{y}=+/-1.83 \mathrm{~m}$.

capable of accessing this area. The overall agreement of the radial velocities, Figure 10, and the tangential velocities, see Figure 11, are very similar to the agreement observed for the axial velocity. Again, the upstream profiles behave much more smoothly, while the downstream profiles clearly capture the discrete structures generated by the rotor blade wakes.

As discussed initially, the good agreement between measured and computed velocities upstream and downstream of the rotor is surprising based on the poor agreement between computed and measured loads on the actual rotor. This combined with the fact that prescribing the load from the measurements to an Actuator Disc computations results in worse agreement of the velocity profiles, may indicate problems with the measured loads. 

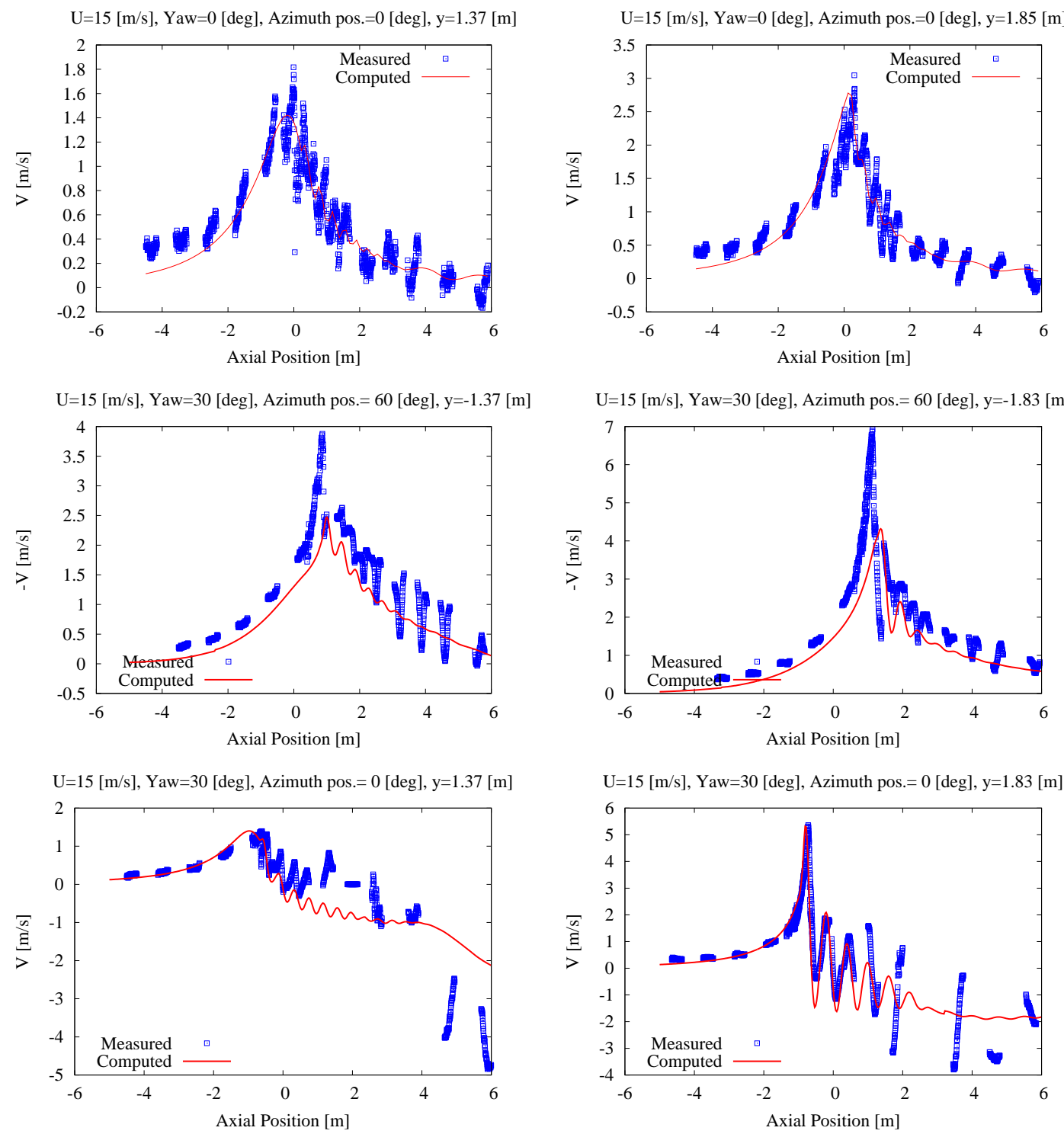

Figure 7: Comparison of axial transects of measured and computed V-velocity in the horizontal plane for the $15 \mathrm{~m} / \mathrm{s}$ axial flow case, top row. The center and bottom row show the $15 \mathrm{~m} / \mathrm{s}$ 30 degrees yaw case for negative and positive $y$-values respectively. The left column shows the inner most line $y=+/-1.37 \mathrm{~m}$ while the right column shows the outermost line $\mathrm{y}=+/-1.83 \mathrm{~m}$.

\section{Conclusion}

The present study documents the level of agreement that can be obtained between experimental data and a state of the art CFD solver for a wind turbine rotor in yawed operation. The computations show that within one rotor diameter downstream of the rotor, excellent agreement can be obtained for all three velocity components as illustrated by the axial transects. Additionally, the radial profiles extracted immediately upstream and downstream of the rotor show an excellent agreement of the velocity field in the proximity of the rotor. Even though the present study is only based on comparison with a single experiment, the good agreement is very encouraging for application of CFD predictions for wake studies. The study additionally showed a large deviation in the region of the yawed flow where the experimental data is heavily influenced by the 

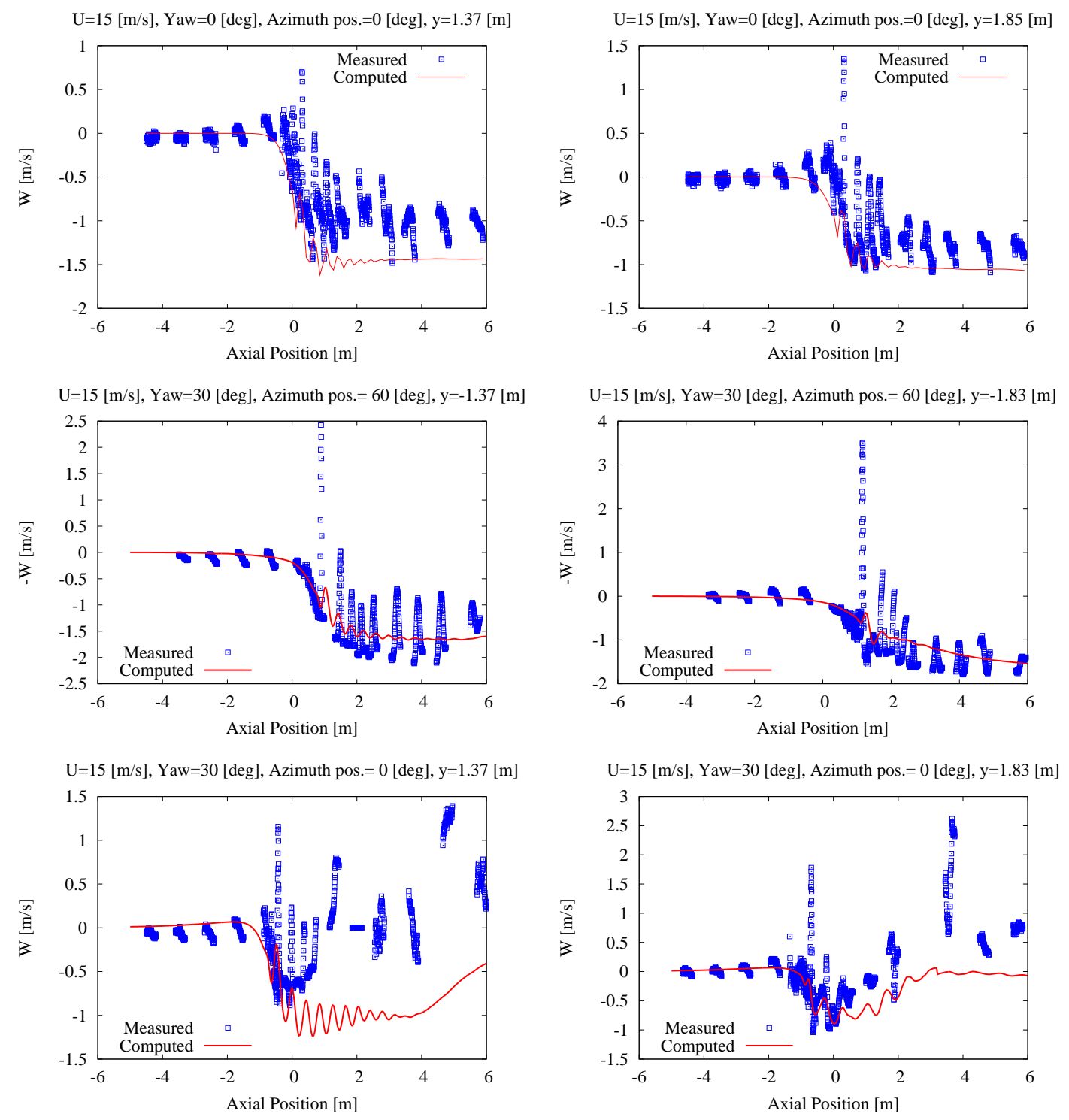

Figure 8: Comparison of axial transects of measured and computed W-velocity in the horizontal plane for the $15 \mathrm{~m} / \mathrm{s}$ axial and 30 degrees yaw case. The center and bottom row show the $15 \mathrm{~m} / \mathrm{s}$ 30 degrees yaw case for negative and positive $y$-values respectively. The left column shows the inner most line $y=+/-1.37 \mathrm{~m}$ while the right column shows the outermost line $\mathrm{y}=+/-1.83 \mathrm{~m}$.

shadow/wake effect of the large nacelle of the MEXICO rotor, and indicates that the nacelle needs to be included in future yaw studies of the MEXICO turbine.

\section{Acknowledgements}

The work was partially funded by the Danish Council for Strategic Research (DSF), under contract 2104-09-0026, Center for Computational Wind Turbine Aerodynamics and Atmospheric Turbulence. Computations were made possible by the use of the PC-cluster provided by the Danish Center for Scientific Computing (DCSC) and the Risø-DTU central computing facility. 

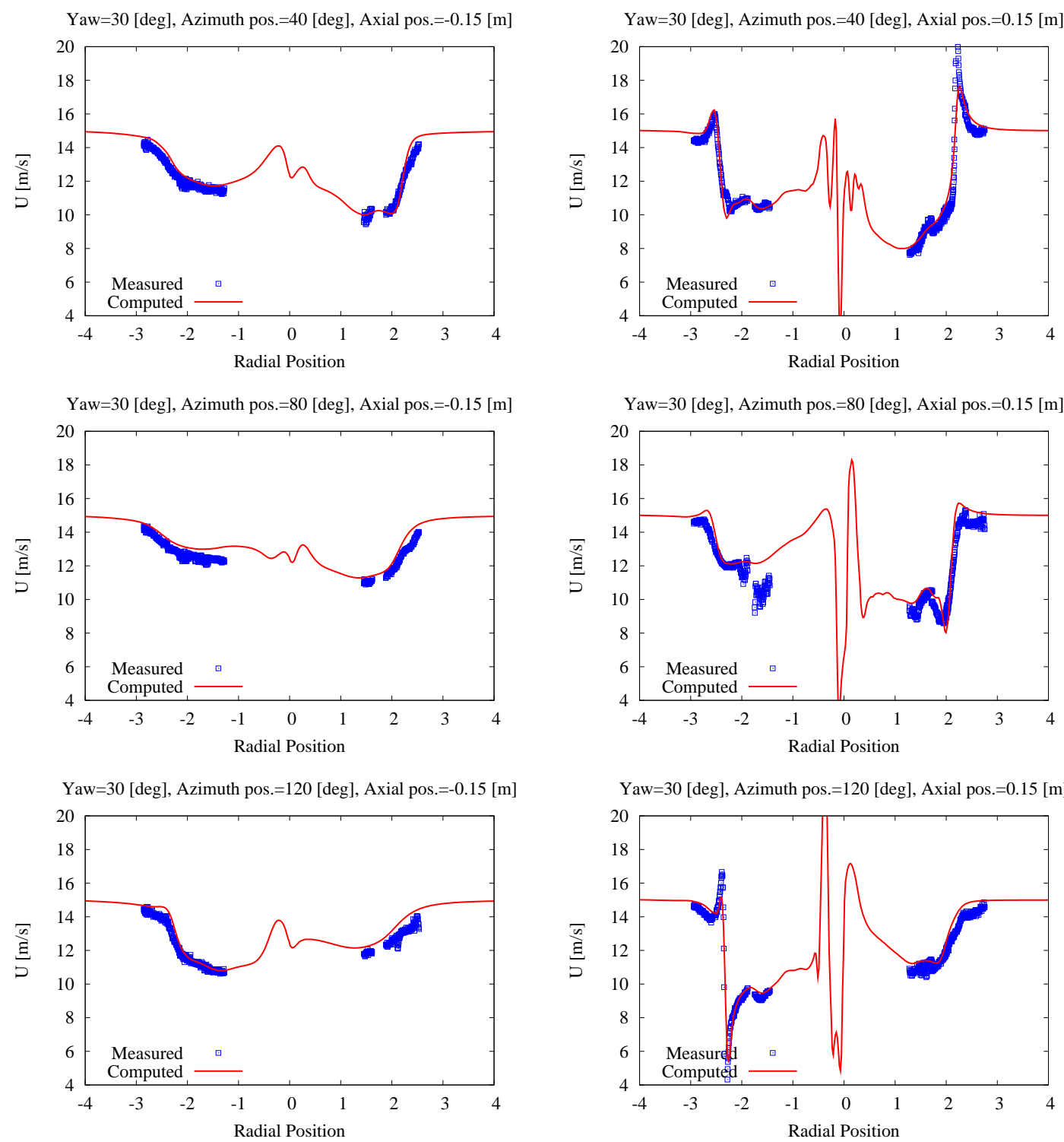

Figure 9: Comparison of radial profiles of measured and computed U-velocity (axial velocity) in the horizontal plane for the $15 \mathrm{~m} / \mathrm{s}, 30$ degrees yawed case. The left column shows the radial profiles $0.15 \mathrm{~m}$ upstream of the rotor, while the right column shows radial profiles $0.15 \mathrm{~m}$ downstream of the rotor. 

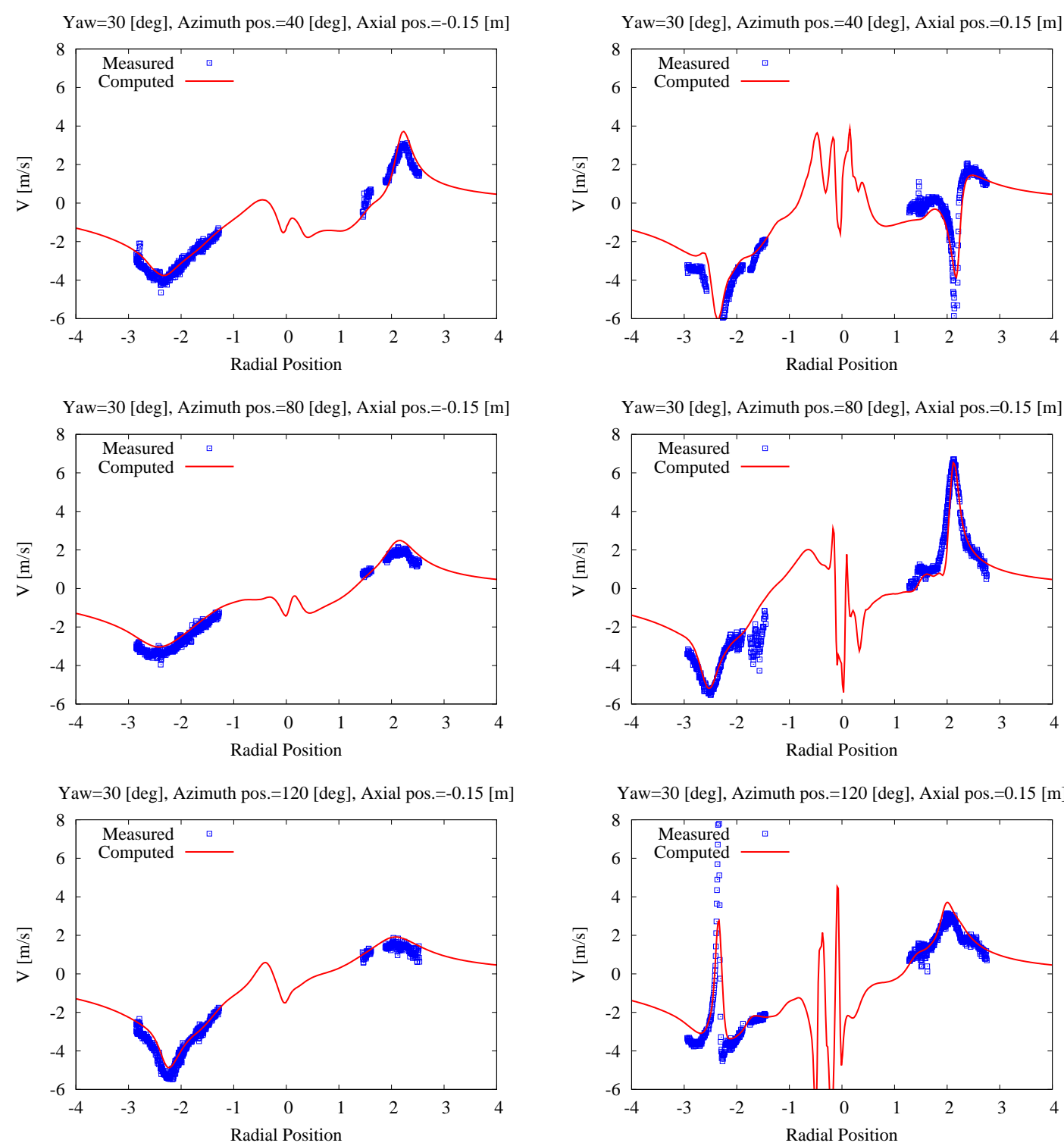

Figure 10: Comparison of radial profiles of measured and computed V-velocity (radial velocity) in the horizontal plane for the $15 \mathrm{~m} / \mathrm{s}, 30$ degrees yaw case. The left column shows the radial profiles $0.15 \mathrm{~m}$ upstream of the rotor, while the right column shows radial profiles $0.15 \mathrm{~m}$ downstream of the rotor. 

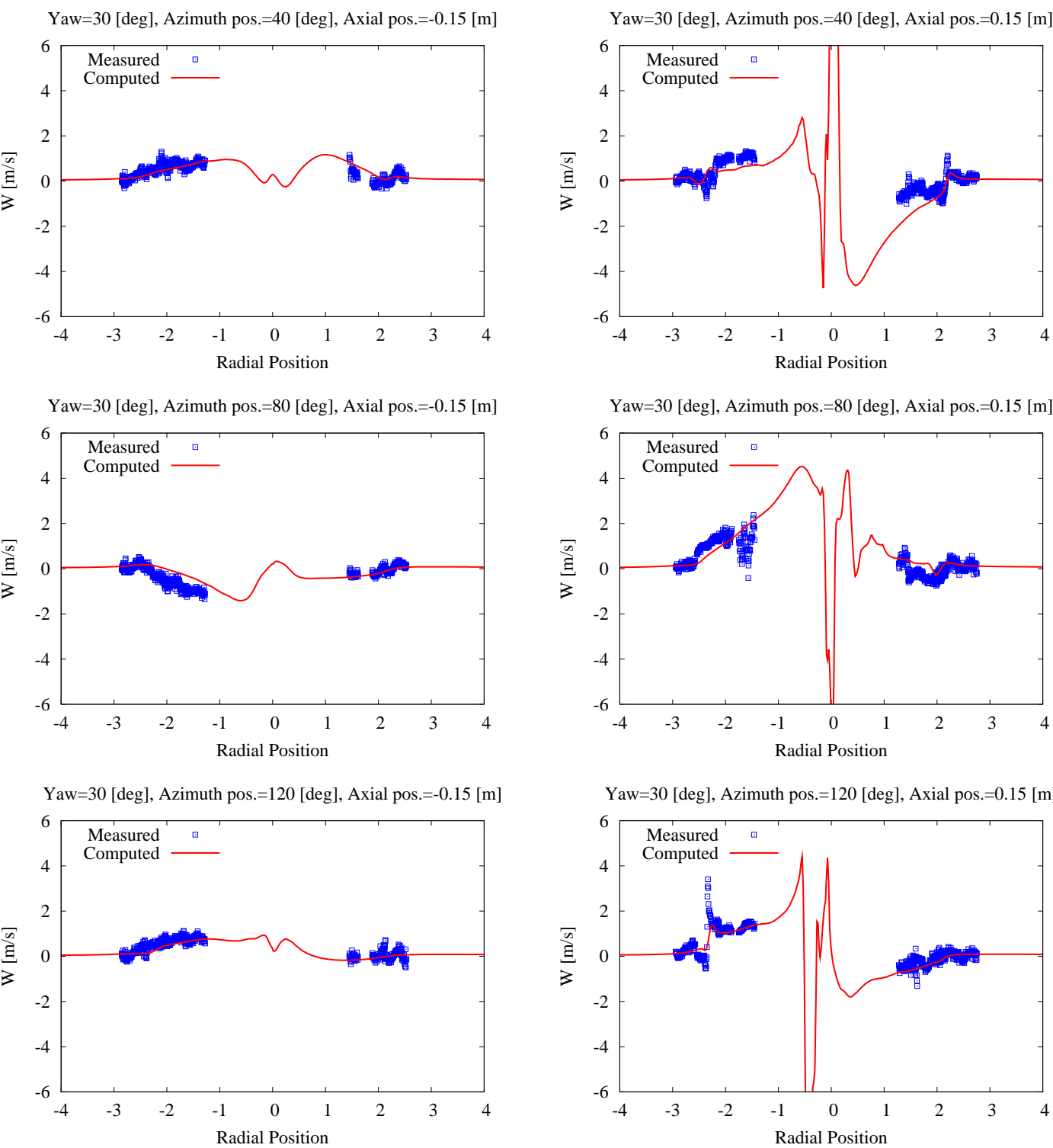

Figure 11: Comparison of radial profiles of measured and computed W-velocity (tangential velocity) in the horizontal plane for the $15 \mathrm{~m} / \mathrm{s}, 30$ degrees yaw case. The left column shows the radial profiles $0.15 \mathrm{~m}$ upstream of the rotor while, the right column shows radial profiles $0.15 \mathrm{~m}$ downstream of the rotor. 


\section{References}

[1] L.J. Vermeer, J.N. Sørensen, and A. Crespo. Wind turbine wake aerodynamics. Progress in Aerospace Sciences, 39:467-510, 2003.

[2] B. Sanderse, S. P. van der Pijl, and B. Koren. Review of computational fluid dynamics for wind turbine wake aerodynamics. Wind Energy, 14, Issue 7:799-819, 2011.

[3] Niels N. Sørensen. CFD modelling of wind turbine aerodynamics. Lecture Series 2007-05. von Karman Institute for Fluid Dynamics, Rhode Saint Genese, 2007. Presented at: von Karman Institute for Fluid Dynamics lecture series : Rhode Saint Genese (BE), 2007.

[4] Xu G. and Sankar L.N. Effects of transition, turbulence and yaw on the performance of horizontal axis wind turbines. AIAA-paper-2000-0048, 2000.

[5] N. N. Sørensen, J. A. Michelsen, and S. Schreck. Application of CFD to wind turbine aerodynamics. In Tsahalis D.T., editor, CD-Rom proceedings. 4. GRACM congress on computational mechanics, Patras, Greece, June 2002.

[6] Helge Aagard Madsen, Niels N. Sørensen, and Scott Schreck. Yaw aerodynamics analyzed with three codes in comparison with experiment. In ASME 2003 Wind Energy Symposium, pages 94-103, Reno, Nevada, USA, January 6-9 2003.

[7] C Tongchitpakdee, S Benjanirat, and LN Sankar. Numerical simulation of the aerodynamics of horizontal axis wind turbines under yawed flow conditions. JOURNAL OF SOLAR ENERGY ENGINEERING-TRANSACTIONS OF THE ASME, 127(4):464-474, NOV 2005.

[8] Frederik Zahle and Niels N. Sørensen. Characterization of the unsteady flow in the nacelle region of a modern wind turbine. Wind Energy, 14(2):271-283, 2011.

[9] Jens Nørkær Sørensen and Wen Zhong Shen. Numerical Modelling of Wind Turbine Wakes. Journal of Fluids Engineering, 124(2):393-399, 2002.

[10] J. N. Sørensen and A. Myken. Unsteady actuator disc model for horizontal axis wind turbines. J. of Wind Engineering and Industrial Aerodynamics, 39:139-149, 1992.

[11] Andreas Bechmann, Niels N. Sørensen, and Frederik Zahle. CFD simulations of the MEXICO rotor. Wind Energy, 14(5):677-689, 2011.

[12] Pierre-Elouan Mikael Réthoré, Niels N. Sørensen, Frederik Zahle, Andreas Bechmann, and Helge Aagaard Madsen. Mexico wind tunnel and wind turbine modelled in cfd. In AIAA Paper 2011-3373. AIAA, 2011. Presented at: AIAA Fluid Dynamics Conference : Honolulu (US) 27-30 Jun, 2011.

[13] T. Lutz, K. Meister, and E. Krämer. Near Wake Studies of the MEXICO Rotor. In EWEC 2011 Proceedings online. EWEC, 2011. Presented at: 2011 European Wind Energy Conference and Exhibition: Brussels (BE), 14-17 Mar, 2011.

[14] F. Grasso and A. Garrel. Near Wake Simulation of Mexico Rotor in Axial and Yawed Flow Conditions with Lifting Line Free Wake Code. ECN-M-11-063, Energy Research Center of the Netherlands, P.O. Box 1, 1755 ZG Petten, 2011.

[15] J. A. Michelsen. Basis3D - a Platform for Development of Multiblock PDE Solvers. Technical Report AFM 92-05, Technical University of Denmark, Department of Fluid Mechanics, Technical University of Denmark, December 1992. 
[16] J. A. Michelsen. Block structured Multigrid solution of 2D and 3D elliptic PDE's. Technical Report AFM 94-06, Technical University of Denmark, Department of Fluid Mechanics, Technical University of Denmark, May 1994.

[17] N. N. Sørensen. General Purpose Flow Solver Applied to Flow over Hills. Risø-R- 827(EN), Risø National Laboratory, Roskilde, Denmark, June 1995.

[18] B. P. Leonard. A stable and accurate convective modelling procedure based on quadratic upstream interpolation. Comput. Meths. Appl. Mech. Eng., 19:59-98, 1979.

[19] N. N. Sørensen. Rotor computations using a 'Steady State' moving mesh. IEA Joint Action Committee on aerodynamics, Annex XI and 20, Annex XI and 20. Aero experts meeting, Pamplona, Spaine, May 2005.

[20] F. R. Menter. Zonal Two Equation k- $\omega$ Turbulence Models for Aerodynamic Flows. AIAA paper 1993-2906, 1993.

[21] N. N. Sørensen. HypGrid2D a 2-D Mesh Generator. Risø-R- 1035-(EN), Risø National Laboratory, Roskilde, Denmark, Feb 1998.

[22] H. Snel, J.G. Schepers, and B. Montgomerie. The MEXICO project (Model Experiments in Controlled Conditions): The database and first results of data processing and interpretation. J. Phys.: Conf. Ser., 75, 2007.

[23] J.G. Schepers and H. Snel. Model Experiments in Controlled Conditions. ECN-E-07-042, Netherlands Energy Research Foundation, ECN, P.O. Box 1, 1755 ZG Petten, 2007.

[24] J.G. Schepers, L. Pascal, and H. Snel. First results from Mexnext: Analysis of detailed aerodynamic measurements on a $4.5 \mathrm{~m}$ diameter rotor placed in the large German Dutch Wind Tunnel DNW. ECN-M-10-045, Energy Research Center of the Netherlands, ECN, P.O. Box 1, 1755 ZG Petten, June 2010. 